Article

\title{
Evaluation and Parameter Optimization of Monthly Net Long-Wave Radiation Climatology Methods in China
}

\author{
Wen Cao ${ }^{1,2,3}$, Chunfeng Duan ${ }^{4, *}$, Shuanghe Shen ${ }^{1}$ and Yun Yao ${ }^{2}$ \\ 1 Jiangsu Key Laboratory of Agricultural Meteorology, Nanjing University of Information Science \& \\ Technology, Nanjing 210044, China; sgfxxy_0@163.com (W.C.); yqzhr@nuist.edu.cn (S.S.) \\ 2 Atmospheric Science and Satellite Remote Sensing Key Laboratory of Anhui Province, Anhui Meteorological \\ Institute, Hefei 230031, China; yaoyun358@126.com \\ 3 Anhui Agrometeorological Center, Hefei 230031, China \\ 4 Anhui Climate Center, Hefei 230031, China \\ * Correspondence: dcf118@126.com; Tel.: +86-551-6229-0267
}

Academic Editor: Richard Müller

Received: 4 March 2017; Accepted: 17 May 2017; Published: 23 May 2017

\begin{abstract}
Based on surface radiation balance data and meteorological observations at 19 radiation stations in China from 1993 to 2012, we assessed the applicability of seven empirical formulas for the estimation of monthly surface net long-wave radiation $\left(R_{\mathrm{nl}}\right)$. We then established a revised method applicable to China by re-fitting the formula using new observational data. The iterative solution method and the multivariate regression analysis method with the minimum root mean square error (RMSE) were used as the objective functions in the revised method. Meanwhile, the accuracy of the CERES (Clouds and the Earth's Radiant Energy System) estimated $R_{\mathrm{nl}}$ was also evaluated. Results show that monthly $R_{\mathrm{nl}}$ over China was underestimated by the seven formulas and the CERES data. The Tong Hongliang formula with lowest errors was the best among the seven formulas for estimating $R_{\mathrm{nl}}$ over China as a whole, followed by the Penman and the Deng Genyun formulas. The estimated $R_{\mathrm{nl}}$ based on the CERES data also showed relatively higher precision in accordance with the three formulas mentioned above. The FAO56-PM formula (Penman-Monteith formula recommended in the No. 56 report of the Food and Agriculture Organization) without calibration was not applicable to China due to its low accuracy. For individual stations, the Deng Genyun formula was the most accurate in the eastern plain area, while the Tong Hongliang formula was suitable for the plateau. Regional formulas were established based on the geographical distribution of water vapor pressure and elevation over China. The revised national and regional formulas were more accurate than the seven original formulas and the CERES data. Furthermore, the regional formulas produced smaller errors than the national formula at most of the stations. The regional formulas were clearly more accurate than the Deng Genyun formula at stations in Northwestern China and on the Tibetan Plateau. They were also more accurate than the Tong Hongliang formula at the stations located in the eastern area. Therefore, the regional formulas developed in this study are recommended as the standard climatology formulas to calculate monthly $R_{\mathrm{nl}}$ over China.
\end{abstract}

Keywords: net long-wave radiation; evaluation; optimization; method; China

\section{Introduction}

Surface net long-wave radiation $\left(R_{\mathrm{nl}}\right)$ represents the difference between the upward long-wave radiation emitted from the surface and the downward long-wave radiation from the atmosphere [1]. It is the quantity of heat loss from the ground surface through $R_{\mathrm{nl}}$ exchange [2]. $R_{\mathrm{nl}}$ is one of the 
important components to the Earth's surface radiation balance, and the energy exchange between the ground and the atmosphere. Knowing $R_{\mathrm{nl}}$ is necessary for many meteorological studies, e.g., the forecasting of diurnal temperature variations, minimum air temperatures, nocturnal frosts, and fog [3]. Compared with other components of the radiation balance, although $R_{\mathrm{nl}}$ is difficult to observe directly, which is mainly limited by the lack of sophisticated instrumentation, it still can be determined from components of the radiation balance observations using the surface radiation balance equation at a radiation station [2]. However, the stations with complete radiation balance observations are relatively rare, thus, large-scale and long-term $R_{\mathrm{nl}}$ is difficult to obtain in China. Using empirical or semi-empirical radiation formulas, estimating $R_{\mathrm{nl}}$ could complement the above limits of $R_{\mathrm{nl}}$ in time and space. Empirical formulas are the simplest methods to estimate $R_{\mathrm{nl}}$, compared with, e.g., remote sensing, linear interpolation, and neural networks [4]. The estimated $R_{\mathrm{nl}}$ can be applied in several fields, such as calculating evapotranspiration.

The surface net long-wave radiation is influenced by surface temperature, air temperature, water vapor pressure, and cloud cover. Many different empirical or semi-empirical formulas have been proposed for $R_{\mathrm{nl}}$ using routine observations of these meteorological factors. The formula of Angstrom [5] estimated $R_{\mathrm{nl}}$ from air temperature, water vapor pressure, and cloud cover. From the 1930s to the 1950s, cloud cover was replaced by relative sunshine duration in the formulas of Brunt [6], Верлянд [7], and Penman [8]. The formulas of Swinbank [9] and Idso [10] were based on air temperature and cloud cover. The Food and Agriculture Organization (FAO) of the United Nations proposed a revised formula based on the Penman method in the Irrigation and Drainage Papers No. 24 [11] (hereafter FAO24) and No. 56 [12] (hereafter FAO56-PM). The FAO56-PM formula has been applied extensively and globally. The accuracy of the common net long-wave radiation equations adopted in Penman-type evapotranspiration formulas was examined in Japan based on observations $[13,14]$. Regional formulas were established separately for plains and plateaus in China by Tong using measured air temperature, sunshine duration, and water vapor pressure [15]. The Penman method was improved by Deng based on observed data at the Beijing Radiation Station in China [16]. Formulas to estimate $R_{\mathrm{nl}}$ on the Tibetan Plateau were provided by Ji et al. [17] and Li et al. [18]. The variation characteristics and empirical formulas for estimating the net long-wave radiation flux over the oceans were also studied [19-24].

In recent years, less attention has been paid to the climatological estimation of $R_{\mathrm{nl}}$ compared with that of solar radiation. Furthermore, the empirical or semi-empirical formulas for $R_{\mathrm{nl}}$ have been rarely studied because of the lack of measured values, and the FAO56-PM formula has been applied in most studies over China [25-33] without calibration. However, the parameterization schemes of existing formulas characterized the atmospheric and surface conditions of certain spaces and periods, and are probably not appropriate to China based on the new observations. Thus, due to climate change and regional specificity, calibration must be carried out to improve empirical coefficients to estimate $R_{\mathrm{nl}}$ more accurately in China. Where measurements of the surface radiation balance are available, calibration of $R_{\mathrm{nl}}$ can be conducted. The objective of this study was to assess the applicability of the existing seven empirical formulas for estimating $R_{\mathrm{nl}}$ and make a regional calibration using radiation measurements over China to improve the performance of the method for estimating $R_{\mathrm{nl}}$ in China. The satellite estimated datasets of long-wave radiation of the Clouds and Earth's Radiant Energy System (CERES) have been widely used in various applications. The accuracy of the surface net long-wave radiation fluxes from CERES Energy Balanced And Filled (EBAF)-Surface Edition 2.8 (National Aeronautics and Space Administration, Washington, DC, USA) is also evaluated along with others from the seven formulas mentioned above. 


\section{Data and Methods}

\subsection{Data}

High-quality monthly observations of net radiation, solar radiation, reflected radiation, maximum and minimum air temperature, water vapor pressure, and sunshine duration were collected at 19 radiation stations in China during 1993-2012 (Table 1). The 19 stations are nearly uniformly distributed across the whole country (Figure 1). The radiation data were measured using automatic thermoelectric pyranometers. The observed data, latitude, longitude, and elevation of the stations were provided by the National Meteorological Information Center (NMIC) of the China Meteorological Administration (CMA). Radiation and meteorological measurements made at the stations were carefully checked using quality control procedures, and quality control flags were supplied with the data by NMIC. In order to ensure the veracity of the evaluation, $4.56 \%$ of the total samples were removed if the radiation observation is missing. Some missing meteorological data were estimated by averaging the observed values over 1993-2012 at the same station.

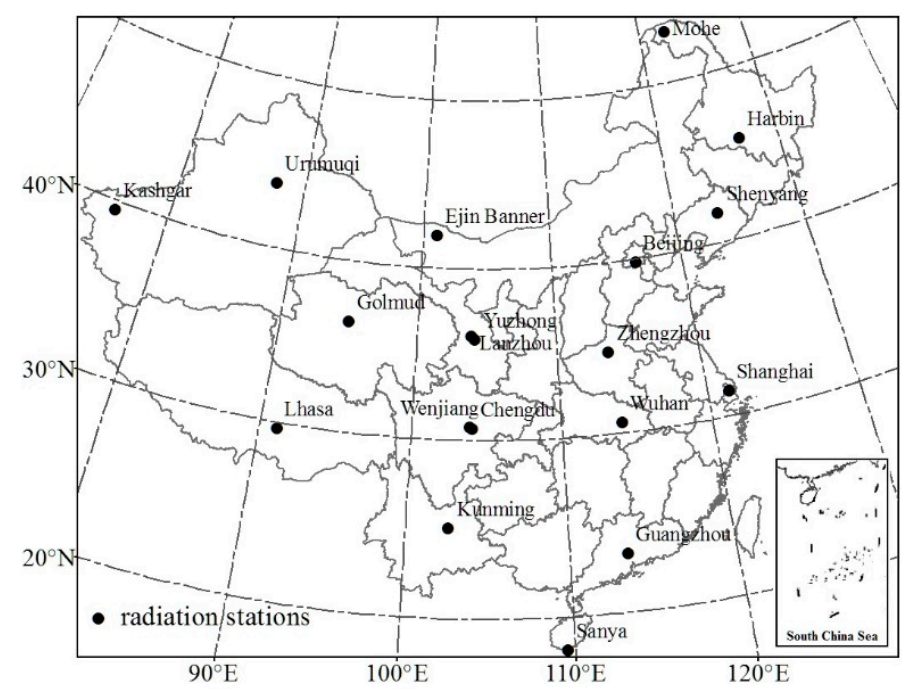

Figure 1. Distribution of the nineteen radiation stations in China.

As one of the highest priority scientific satellite instruments developed for NASA's Earth Observing System (EOS), CERES sensors were placed onboard the Terra and Aqua satellites. EBAF-Surface Ed 2.8 is one of the CERES products, which provides monthly and climatological averages of computed fluxes of the Earth's surface. CERES EBAF-Surface Ed 2.8 data of surface net long-wave radiation are available online from the CERES website [34]. The CERES data products use meteorological assimilation data from the Goddard Earth Observing System (GEOS-4 and 5) Data Assimilation System reanalysis to characterize the atmospheric state. GEOS-4 was used from March 2000 through December 2007, and GEOS-5 was used beginning in January 2008. The CERES EBAF-Surface Ed 2.8 data during the period of March 2000 to December 2012 were interpolated into the station points listed in Table 1 by bi-linear interpolation, so they could be compared with the standard $R_{\mathrm{nl}}$ over China.

Observations of the surface energy balance in China were initiated at the radiation stations in January 1993, however, observations of the $R_{\mathrm{nl}}$ were not made at that time. $R_{\mathrm{nl}}$ at a radiation station can be determined from components of the radiation balance observations using the surface radiation balance equation:

$$
R_{\mathrm{nl}}=R_{\mathrm{s}}-R_{\mathrm{k}}-R_{\mathrm{n}}
$$

where $R_{\mathrm{n}}$ is the net radiation, $R_{\mathrm{s}}$ is the solar radiation, $R_{\mathrm{k}}$ is the reflected radiation, and $R_{\mathrm{nl}}$ is the net long-wave radiation. $R_{\mathrm{s}}$ represents the incoming radiation energy, and $R_{\mathrm{k}}$ and $R_{\mathrm{nl}}$ are the short-wave 
and long-wave radiation energy loss, respectively. $R_{\mathrm{n}}, R_{\mathrm{s}}$, and $R_{\mathrm{k}}$ have been measured using automatic thermoelectric pyranometers in China since January 1993.

From Equation (1), we obtained monthly $R_{\mathrm{nl}}$ values based on the observations of $R_{\mathrm{n}}, R_{\mathrm{s}}$, and $R_{\mathrm{k}}$ at the 19 solar radiation stations from 1993 to 2012 as a standard to assess the applicability of the existing seven empirical formulas for computing $R_{\mathrm{nl}}$, and to establish an optimum net long-wave radiation formula for China. Mean annual values of monthly standard $R_{\mathrm{nl}}$ for each station are listed in Table 1. The values of monthly standard $R_{\mathrm{nl}}$ ranged from 40.3 to $121.5 \mathrm{~W} / \mathrm{m}^{2}$ at the 19 stations. $R_{\mathrm{nl}}$ decreased, in general, from Southeast to Northwest China. Lower $R_{\mathrm{nl}}$ occurred in Sichuan Province (Chengdu and Wenjiang), and higher values occurred on the Tibetan Plateau (Golmud and Lhasa) and the northwestern part of Inner Mongolia (Ejin Banner). The range of values and the spatial distribution were similar to some previous studies [35-37] and NCEP (National Centers for Environmental Prediction) reanalysis data. Meanwhile, as shown in Table 1, the standard $R_{\mathrm{nl}}$ increased with the station altitude, especially when the altitude above $1000 \mathrm{~m}$. The evolution of standard $R_{\mathrm{nl}}$ at some stations (e.g., Beijing and Ejin Banner) was shown in Figure 2, and it can be seen that the values increased during spring, reaching a maximum in summertime and a minimum in winter. Monthly minimum $R_{\mathrm{nl}}$ varied between 0 and $50.0 \mathrm{~W} / \mathrm{m}^{2}$, and the maximum values were between 200.0 and $250.0 \mathrm{~W} / \mathrm{m}^{2}$. The standard $R_{\mathrm{nl}}$ at Lhasa station, which were $116.4,85.8$, and $78.7 \mathrm{~W} / \mathrm{m}^{2}$ from June to August, respectively, agreed with the measured values of the first and second Tibetan Plateau Meteorology Scientific Experiment [38,39]. The standard $R_{\mathrm{nl}}$ at Wuhan station was $48.6 \mathrm{~W} / \mathrm{m}^{2}$, similar to that at the nearby Shouxian station, where the observed values were supported by the Atmospheric Radiation Measurement (ARM) Program. These comparisons showed that the standard monthly $R_{\mathrm{nl}}$ determined from the components of the radiation balance observations using the surface radiation balance equation were credible. In addition, this method was widely applied to calculate $R_{\mathrm{nl}}$ as a standard to establish a climatology formula and temporal-spatial distribution analysis in several studies [15,36,39-41] due to the lack of directly-observed data. This confirmed that the $R_{\mathrm{nl}}$ obtained in this study can be applied as the standard for the parameter evaluation and modification of the $R_{\mathrm{nl}}$ climatology formula.

Table 1. Radiation stations used in the study.

\begin{tabular}{ccccccc}
\hline No. & Station & $\begin{array}{c}\text { Latitude } \\
\left({ }^{\circ} \mathbf{N}\right)\end{array}$ & $\begin{array}{c}\text { Longitude } \\
\left({ }^{\circ} \mathbf{E}\right)\end{array}$ & $\begin{array}{c}\text { Elevation } \\
(\mathbf{m})\end{array}$ & $\begin{array}{c}\text { Observed } \\
\text { Period }\end{array}$ & $\begin{array}{c}\text { Standard } \\
\boldsymbol{R}_{\mathbf{n l}}\left(\mathbf{W} / \mathbf{m}^{\mathbf{2}}\right)\end{array}$ \\
\hline 1 & Beijing & 39.80 & 116.47 & 31.3 & $1993-2012$ & 76.0 \\
2 & Chengdu & 30.67 & 104.02 & 506.1 & $1993-2003$ & 40.4 \\
3 & Ejin Banner & 41.95 & 101.07 & 940.5 & $1993-2012$ & 121.5 \\
4 & Golmud & 36.42 & 94.92 & 2807.6 & $1993-2012$ & 106.4 \\
5 & Guangzhou & 23.22 & 113.48 & 70.7 & $1993-2012$ & 44.7 \\
6 & Harbin & 45.75 & 126.77 & 142.3 & $1993-2012$ & 73.9 \\
7 & Kashgar & 39.47 & 75.98 & 1289.4 & $1993-2012$ & 90.8 \\
8 & Kunming & 25.00 & 102.65 & 1888.1 & $1993-2012$ & 71.2 \\
9 & Lanzhou & 36.05 & 103.88 & 1517.2 & $1993-2004$ & 81.0 \\
10 & Lhasa & 29.67 & 91.13 & 3648.9 & $1993-2012$ & 116.1 \\
11 & Mohe & 52.97 & 122.52 & 433.0 & $1993-2012$ & 65.3 \\
12 & Sanya & 18.22 & 109.58 & 419.4 & $1993-2012$ & 64.6 \\
13 & Shanghai & 31.40 & 121.45 & 5.5 & $1993-2012$ & 55.0 \\
14 & Shenyang & 41.73 & 123.52 & 49.0 & $1993-2012$ & 74.0 \\
15 & Urumuqi & 43.78 & 87.65 & 935.0 & $1993-2012$ & 85.1 \\
16 & Wenjiang & 30.75 & 103.87 & 547.7 & $2004-2012$ & 40.3 \\
17 & Wuhan & 30.60 & 114.05 & 23.6 & $1993-2012$ & 48.6 \\
18 & Yuzhong & 35.87 & 104.15 & 1874.4 & $2005-2012$ & 86.9 \\
19 & Zhengzhou & 34.72 & 113.65 & 110.4 & $1993-2012$ & 64.2 \\
\hline
\end{tabular}



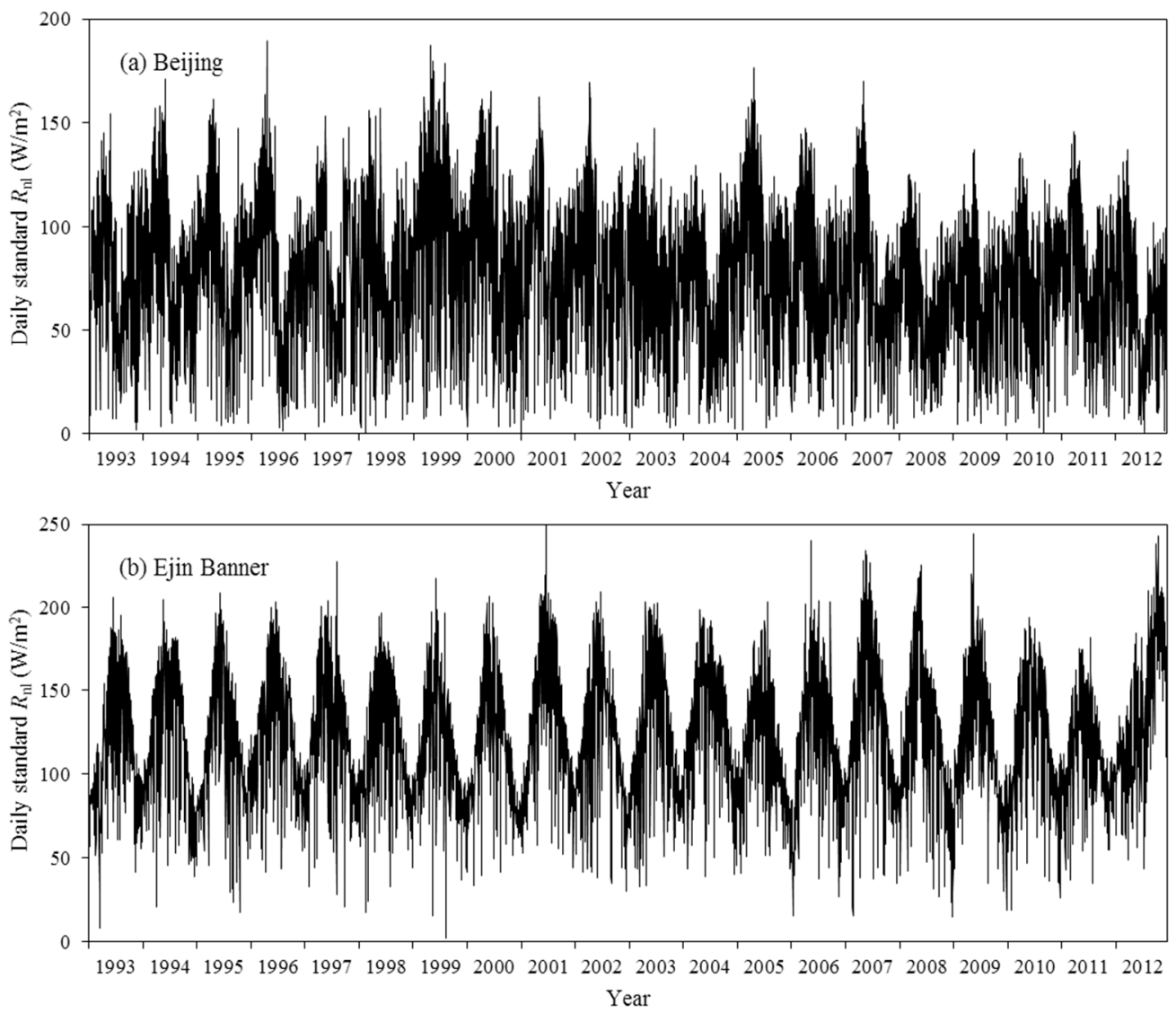

Figure 2. Evolution of daily net long-wave radiation for the period from January 1993 to December 2012 at Beijing (a) and Ejin Banner (b).

\subsection{Methods}

\subsubsection{Empirical Formulas}

We tested the application of the seven existing empirical formulas for computing the monthly surface net long-wave radiation $\left(R_{\mathrm{nl}}\right)$. The magnitude of $R_{\mathrm{nl}}$ is influenced by air temperature, surface temperature, humidity, and cloud cover [42]. These formulas were derived on a physical basis and obtained by empirical correlations, and the $R_{\mathrm{nl}}$ was estimated from maximum and minimum air temperature, water vapor pressure, and relative sunshine duration. $R_{\mathrm{nl}}$ can be estimated using the following equation:

$$
R_{\mathrm{nl}}=\sigma\left(\frac{T_{\min }{ }^{4}+T_{\max }^{4}}{2}\right)\left(a_{0}+a_{1} \sqrt{e_{\mathrm{a}}}\right)\left(b_{0}+\left(1-b_{0}\right) \frac{n_{\mathrm{s}}}{N_{\mathrm{s}}}\right)
$$

where $R_{\mathrm{nl}}$ is the net long-wave radiation $\left(\mathrm{W} / \mathrm{m}^{2}\right), \sigma$ is the Stefan-Boltzmann constant $\left(5.67 \times 10^{-8} \mathrm{~W} /\left(\mathrm{K}^{4} \cdot \mathrm{m}^{2}\right)\right), T_{\min }$ is the minimum absolute temperature $(\mathrm{K}), T_{\max }$ is the maximum absolute temperature $(\mathrm{K}), e_{\mathrm{a}}$ is the water vapor pressure $(\mathrm{kPa}), n_{\mathrm{s}}$ is the actual sunshine duration (hour), $N_{\mathrm{S}}$ is the maximum possible sunshine duration (hour), $n_{\mathrm{S}} / N_{\mathrm{s}}$ is the relative sunshine duration, and $a_{0}$, $a_{1}\left(\mathrm{kPa}^{-1}\right)$, and $b_{0}$ are the coefficients of the parameterization schemes. $N_{\mathrm{s}}$ was calculated based on latitude, elevation, and the number of the day of the year according to the FAO56 report [12].

In this study, the seven common formulas (Table 2) to estimate $R_{\mathrm{nl}}$ were collected from Brunt [6], Penman [8], Верлянд [7], FAO24 [11], FAO56-PM [12], Deng Genyun [16], and Tong Hongliang [15]. The unit of $e_{\mathrm{a}}$ was converted to $\mathrm{kPa}$, and the minimum and maximum temperatures were used for comparison. 
Table 2. The seven common formulas to calculate monthly net long-wave radiation.

\begin{tabular}{|c|c|c|c|}
\hline \multicolumn{2}{|c|}{ Formulas } & Equations & No. \\
\hline \multicolumn{2}{|c|}{ Brunt } & $R_{\mathrm{nl}}=\sigma\left(\frac{T_{\min }{ }^{4}+T_{\max }{ }^{4}}{2}\right)\left(0.56-0.291 \sqrt{e_{\mathrm{a}}}\right)\left(0.1+0.9 \frac{n_{\mathrm{s}}}{N_{\mathrm{s}}}\right)$ & (3) \\
\hline \multicolumn{2}{|c|}{ Penman } & $R_{\mathrm{nl}}=\sigma\left(\frac{T_{\min }^{4}+T_{\max }^{4}}{2}\right)\left(0.56-0.250 \sqrt{e_{\mathrm{a}}}\right)\left(0.1+0.9 \frac{n_{\mathrm{s}}}{N_{\mathrm{s}}}\right)$ & (4) \\
\hline \multicolumn{2}{|c|}{ Верлянд } & $R_{\mathrm{nl}}=\sigma\left(\frac{T_{\min }{ }^{4}+T_{\max }{ }^{4}}{2}\right)\left(0.39-0.183 \sqrt{e_{\mathrm{a}}}\right)\left(0.1+0.9 \frac{n_{\mathrm{s}}}{N_{\mathrm{s}}}\right)$ & (5) \\
\hline \multicolumn{2}{|c|}{ FAO24 } & $R_{\mathrm{nl}}=\sigma\left(\frac{T_{\min }^{4}+T_{\max }^{4}}{2}\right)\left(0.34-0.139 \sqrt{e_{\mathrm{a}}}\right)\left(0.1+0.9 \frac{n_{\mathrm{s}}}{N_{\mathrm{s}}}\right)$ & (6) \\
\hline \multicolumn{2}{|c|}{ FAO56-PM } & $R_{\mathrm{nl}}=\sigma\left(\frac{T_{\min }{ }^{4}+T_{\max }{ }^{4}}{2}\right)^{\prime}\left(0.34-0.139 \sqrt{e_{\mathrm{a}}}\right)\left(1.35 \frac{R_{\mathrm{s}}}{R_{s o}}-0.35\right)$ & (7) \\
\hline \multicolumn{2}{|c|}{ Deng Genyun } & $R_{\mathrm{nl}}=\sigma\left(\frac{T_{\min }{ }^{4}+T_{\max }^{4}}{2}\right)\left(0.32-0.082 \sqrt{e_{\mathrm{a}}}\right)\left(0.3+0.7 \frac{n_{\mathrm{s}}}{N_{\mathrm{s}}}\right)$ & $(8)$ \\
\hline \multirow{3}{*}{ Tong Hongliang } & Plain & $R_{\mathrm{nl}}=\sigma\left(\frac{T_{\min }{ }^{4}+T_{\max }^{4}}{2}\right)\left(0.32-0.093 \sqrt{W_{\infty}}\right)\left(0.43+0.57 \frac{n_{\mathrm{s}}}{N_{\mathrm{s}}}\right)$ & (9) \\
\hline & Plateau & $R_{\mathrm{nl}}=\sigma\left(\frac{T_{\min }{ }^{4}+T_{\max }{ }^{4}}{2}\right)\left(0.304-0.021 \sqrt{W_{\infty}}\right)\left(0.1+0.9 \frac{n_{\mathrm{s}}}{N_{\mathrm{s}}}\right) \exp (0.00012 z)$ & (10) \\
\hline & & $W_{\infty}=\left(0.1054+1.513 e_{\mathrm{a}}\right) \exp (0.00006 z)$ & (11) \\
\hline
\end{tabular}

$R_{\mathrm{nl}}, \sigma, T_{\min }, T_{\max }, e_{\mathrm{a}}, n_{\mathrm{s}}$, and $N_{\mathrm{s}}$ represent the same factors and constants as above. $R_{\mathrm{s}}$ is the solar radiation, $R_{\mathrm{so}}$ is the clear-sky solar radiation, and $R_{\mathrm{s}}$ and $R_{\mathrm{so}}$ in the FAO56-PM formula were calculated according to the FAO56 report [12]. $W_{\infty}$ is the atmospheric moisture content calculated based on $e_{\mathrm{a}}$ and $z$ using Equation (11). $Z$ is the elevation $(\mathrm{m})$.

\subsubsection{Analytical Methods}

The performance of the existing and refitted formulas reported here was judged based on the correlation coefficient (R), mean bias error (MBE), mean absolute bias error (MABE), mean absolute percentage error (MAPE), and root mean square error (RMSE) between the estimates and the standard values. The MBE reflects the estimation error, where a positive value means a higher estimate and a negative value means a lower estimate, and a smaller absolute MBE indicates a more accurate method [43-45]. RMSE reflects the estimated sensitivity and extreme effects of samples, with smaller values indicating better accuracy [46]. MBE, MABE, MAPE, and RMSE are calculated by:

$$
\begin{gathered}
\mathrm{MBE}=\frac{\sum_{i=1}^{n}\left(y_{i}-x_{i}\right)}{n} \\
\mathrm{MABE}=\frac{\sum_{i=1}^{n}\left|y_{i}-x_{i}\right|}{n} \\
\mathrm{MAPE}=\frac{\sum_{i=1}^{n}\left(\left|\frac{y_{i}-x_{i}}{x_{i}}\right| \times 100 \%\right)}{n} \\
\mathrm{RMSE}=\sqrt{\frac{\sum_{i=1}^{n}\left(y_{i}-x_{i}\right)^{2}}{n}}
\end{gathered}
$$

where $x_{i}$ is the observation or standard value; $y_{i}$ is the estimate; and $n$ is the number of samples. For the amount of data in this study, 3894 monthly values of radiation and climate factors based on surface observations and 2459 monthly values of CERES EBAF-Surface Ed $2.8 R_{\mathrm{nl}}$ data were used.

\section{Results and Discussion}

\subsection{Assessment of the Existing $R_{n l}$ Empirical Formulas}

Based on the observed data during 1993-2012, the monthly $R_{\mathrm{nl}}$ at the 19 solar radiation stations in China was calculated using the seven formulas listed in Table 2. The average standard $R_{\mathrm{nl}}$ of the 19 stations was $75.4 \mathrm{~W} / \mathrm{m}^{2}$. The average estimated $R_{\mathrm{nl}}$ based on the Penman, Deng Genyun, and Tong Hongliang formulas and CERES data were $69.1,61.0,65.4$ and $64.6 \mathrm{~W} / \mathrm{m}^{2}$, respectively. They 
were much closer to the average standard $R_{\mathrm{nl}}$ than those based on the other four formulas; Brunt, Верлянд, FAO24, and FAO56-PM formulas produced estimated $R_{\mathrm{nl}}$ values of 60.3, 46.1, 44.7, and $42.6 \mathrm{~W} / \mathrm{m}^{2}$, respectively. We also compared the R, MBE, MABE, MAPE, and RMSE of the standard and estimated $R_{\mathrm{nl}}$ based on the seven tested formulas, as well as CERES data for the 19 stations (Figure 3 and Table 3). This showed that the $R_{\mathrm{nl}}$ based on the empirical coefficients recommended in the Deng Genyun formula had the highest $\mathrm{R}$ compared with the standard values (Figure 3f), followed by the Tong Hongliang formula (Figure 3g). The $R_{\mathrm{nl}}$ based on the Brunt formula had the lowest $\mathrm{R}$ (Figure 3a). The MBE of the estimated $R_{\mathrm{nl}}$ was negative for the seven formulas and CERES data, suggesting that $R_{\mathrm{nl}}$ was underestimated by all of the formulas. In particular, the Верлянд, FAO24, and FAO56-PM simulations were much lower than the standard values for most of the samples (Figure 3c-e) compared with those of the other four formulas.
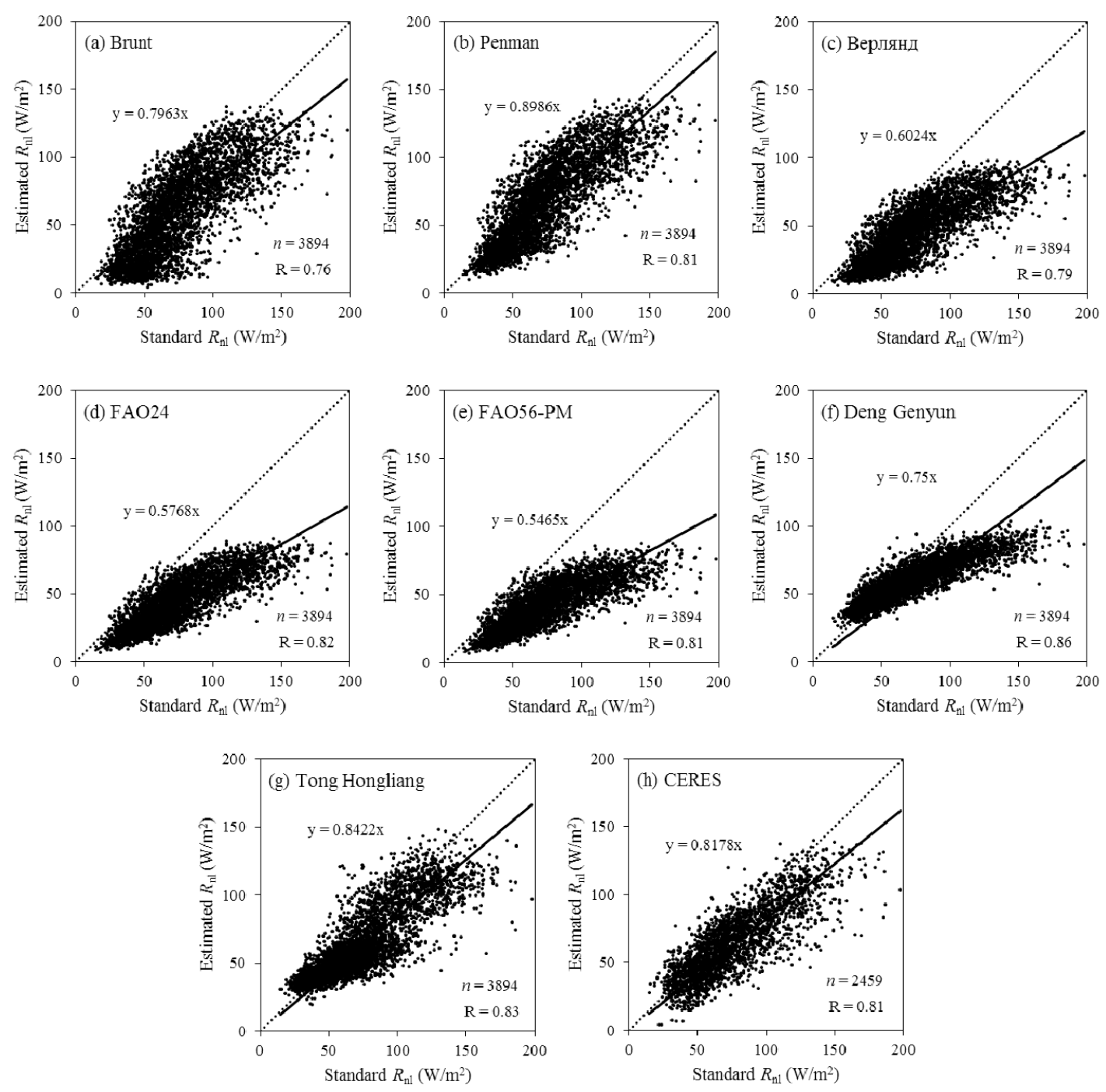

Figure 3. Correlation between the standard and estimated monthly net long-wave radiation based on the seven existing empirical formulas (a) Brunt; (b) Penman; (c) Верлянд; (d) FAO24; (e) FAO56-PM; (f) Deng Genyun; (g) Tong Hongliang) and CERES data $(\mathbf{h})$ at the nineteen radiation stations.

In general, the Tong Hongliang formula had the highest accuracy with the lowest MABE, MAPE, and RMSE among the seven empirical formulas for estimating monthly $R_{\mathrm{nl}}$ over the whole of China, followed by the Penman and the Deng Genyun formulas. The estimated $R_{\mathrm{nl}}$ based on the CERES data also showed relatively higher precision in accordance with these three formulas mentioned above. The 
FAO56-PM formula with the lowest accuracy was not applicable to China. These results agreed with the research of Yin et al. [47]. For individual stations, the accuracy of the Deng Genyun formula was the highest on the eastern plains. Compared with the other six formulas, the Deng Genyun formula had the lowest MABE, MAPE, and RMSE at nine stations, including Beijing, Chengdu, Harbin, Mohe, Sanya, Shanghai, Shenyang, Wenjiang, and Zhengzhou (Table 4). The Deng Genyun formula was, therefore, suitable for stations located on the plain in Eastern China at an altitude of less than $600 \mathrm{~m}$. This was most likely because the empirical constants of the relative sunshine duration $\left(n_{\mathrm{S}} / N_{\mathrm{S}}\right)$ were different from those of the other formulas and correctly described the effect of cloud cover on $R_{\mathrm{nl}}$. Furthermore, the empirical constants derived from the Beijing station data only using the Deng Genyun formula largely fit east China, suggesting that the coefficient was almost the same for this area. The Tong Hongliang formula was more accurate at stations with an elevation greater than $900 \mathrm{~m}$, including Golmud, Kashgar, Kunming, Lanzhou, Urumuqi, and Yuzhong (Table 4). The Tong Hongliang formula was suitable for the plateau area because of the altitude correction that is applied when calculating the atmospheric moisture. The FAO24 and FAO56-PM formulas showed the lowest accuracy at most of the stations.

Table 3. Comparison of the standard and estimated monthly net long-wave radiation based on the seven existing empirical formulas and CERES data.

\begin{tabular}{|c|c|c|c|c|c|}
\hline Formulas & $\mathbf{R}$ & $\operatorname{MBE}\left(W / m^{2}\right)$ & $\operatorname{MABE}\left(W / m^{2}\right)$ & MAPE (\%) & $\operatorname{RMSE}\left(\mathrm{W} / \mathrm{m}^{2}\right)$ \\
\hline Brunt & 0.762 & -15.152 & 21.061 & 30.266 & 26.420 \\
\hline Penman & 0.809 & -6.280 & 15.662 & 22.068 & 19.972 \\
\hline Верлянд & 0.795 & -29.302 & 29.707 & 39.294 & 34.967 \\
\hline FAO24 & 0.817 & -30.733 & 30.913 & 39.826 & 36.116 \\
\hline FAO56-PM & 0.809 & -32.771 & 32.904 & 42.078 & 38.426 \\
\hline Deng Genyun & 0.860 & -14.441 & 17.871 & 20.965 & 24.606 \\
\hline Tong Hongliang & 0.827 & -10.027 & 15.107 & 19.562 & 20.092 \\
\hline CERES & 0.814 & -11.941 & 16.454 & 21.819 & 21.612 \\
\hline
\end{tabular}

Table 4. Order of formula precisions for calculating the monthly net long-wave radiation at nineteen radiation stations in China.

\begin{tabular}{|c|c|c|c|c|c|c|c|}
\hline Station $\quad$ Order & 1 & 2 & 3 & 4 & 5 & 6 & 7 \\
\hline Beijing & Deng & Penman & Tong & Brunt & Верлянд & FAO24 & FAO56 \\
\hline Chengdu & Deng & Tong & Penman & Brunt & FAO24 & FAO56 & Верлянд \\
\hline Ejin Banner & Penman & Brunt & Tong & Deng & Верлянд & FAO24 & FAO56 \\
\hline Golmud & Tong & Penman & Brunt & Deng & Верлянд & FAO24 & FAO56 \\
\hline Guangzhou & Tong & Deng & Penman & FAO24 & FAO56 & Brunt & Верлянд \\
\hline Harbin & Deng & Penman & Tong & Brunt & Верлянд & FAO24 & FAO56 \\
\hline Kashgar & Tong & Deng & Penman & Brunt & Верлянд & FAO24 & FAO56 \\
\hline Kunming & Tong & Deng & Penman & Brunt & Верлянд & FAO24 & FAO56 \\
\hline Lanzhou & Tong & Penman & Deng & Brunt & Верлянд & FAO24 & FAO56 \\
\hline Lhasa & Penman & Tong & Brunt & Deng & Верлянд & FAO24 & FAO56 \\
\hline Mohe & Deng & Tong & Penman & Верлянд & Brunt & FAO24 & FAO56 \\
\hline Sanya & Deng & Tong & Penman & FAO24 & FAO56 & Верлянд & Brunt \\
\hline Shanghai & Deng & Tong & Penman & Brunt & FAO24 & FAO56 & Верлянд \\
\hline Shenyang & Deng & Penman & Tong & Brunt & Верлянд & FAO24 & FAO56 \\
\hline Urumuqi & Tong & Penman & Brunt & Deng & Верлянд & FAO24 & FAO56 \\
\hline Wenjiang & Deng & Tong & Penman & Brunt & FAO24 & Верлянд & FAO56 \\
\hline Wuhan & Tong & Deng & Penman & Brunt & FAO24 & FAO56 & Верлянд \\
\hline Yuzhong & Tong & Penman & Brunt & Deng & Верлянд & FAO24 & FAO56 \\
\hline Zhengzhou & Deng & Tong & Penman & Brunt & Верлянд & FAO24 & FAO56 \\
\hline
\end{tabular}




\subsection{Establishment of Optimal $R_{n l}$ Empirical Formulas}

The partial correlation analysis showed that the estimated errors of the seven tested formulas were mainly related to water vapor pressure or elevation, except for FAO56-PM. Therefore, water vapor pressure and elevation were the two most critical factors affecting the $R_{\mathrm{nl}}$ estimate. In this paper, apart from revising the formula for the whole of China (hereafter, the national formula), we also established revised regional formulas for the eastern and northwestern areas and the Tibetan Plateau, according to the geographical distribution of water vapor pressure and elevation over China.

First, the monthly standard net long-wave radiation at the 19 stations was calculated based on the surface radiation balance equation using observations from 1993 to 2012. Second, the parameter $b_{0}$ in Equation (2) was iterated with a step of 0.01 from 0 to 1 . The maximum and minimum air temperature, water vapor pressure, and relative sunshine duration were used as inputs to obtain $a_{0}$ and $a_{1}$ using multivariate regression for different $b_{0}$. Finally, the $R_{\mathrm{nl}}$ of different $b_{0}, a_{0}$, and $a_{1}$ was estimated. The best $b_{0}, a_{0}$, and $a_{1}$ was determined using the minimum RMSE between the estimate and standard values as the objective function. Considering the limited data, some samples from odd years $(n=1949)$ were used to calibrate the parameters, and the other samples from even years $(n=1945)$ were preserved to validate an optimum net long-wave radiation formula calibration, which is called the validated $R_{\mathrm{nl}}$. The national and regional formulas are listed in Table 5.

The correlation coefficient, $\mathrm{R}$, between the validated and standard $R_{\mathrm{nl}}$ for national and regional formulas, were 0.85 and 0.87 , respectively (Figure 4), which were both higher than those for most of the existing seven formulas evaluated in this study. Some discrepancies existed with $R_{\mathrm{nl}}$ values greater than $120 \mathrm{~W} / \mathrm{m}^{2}$. However, the two formulas provided a reasonable simulated $R_{\mathrm{nl}}$, and the regression equation could adequately describe $R_{\mathrm{nl}}$ and can be used to analyze $R_{\mathrm{nl}}$. Table 6 presents the MBE, MABE, MAPE, and RMSE of the standard and validated $R_{\mathrm{nl}}$ based on national and regional formulas for the 19 radiation stations. The negative MBE, with an average absolute value of approximately $1.0 \mathrm{~W} / \mathrm{m}^{2}$ for the 19 stations, illustrates that $R_{\mathrm{nl}}$ was slightly underestimated by the two revised formulas. Moreover, the validated $R_{\mathrm{nl}}$ had the lowest average MAPE and RMSE of the 19 stations compared with the other formulas listed in Table 2. In general, the $R_{\mathrm{nl}}$ based on the two revised formulas was relatively more accurate compared with the other calculations over China. Therefore, further modifications must be made using meteorological observations when the $R_{\mathrm{nl}}$ formulas are applied.
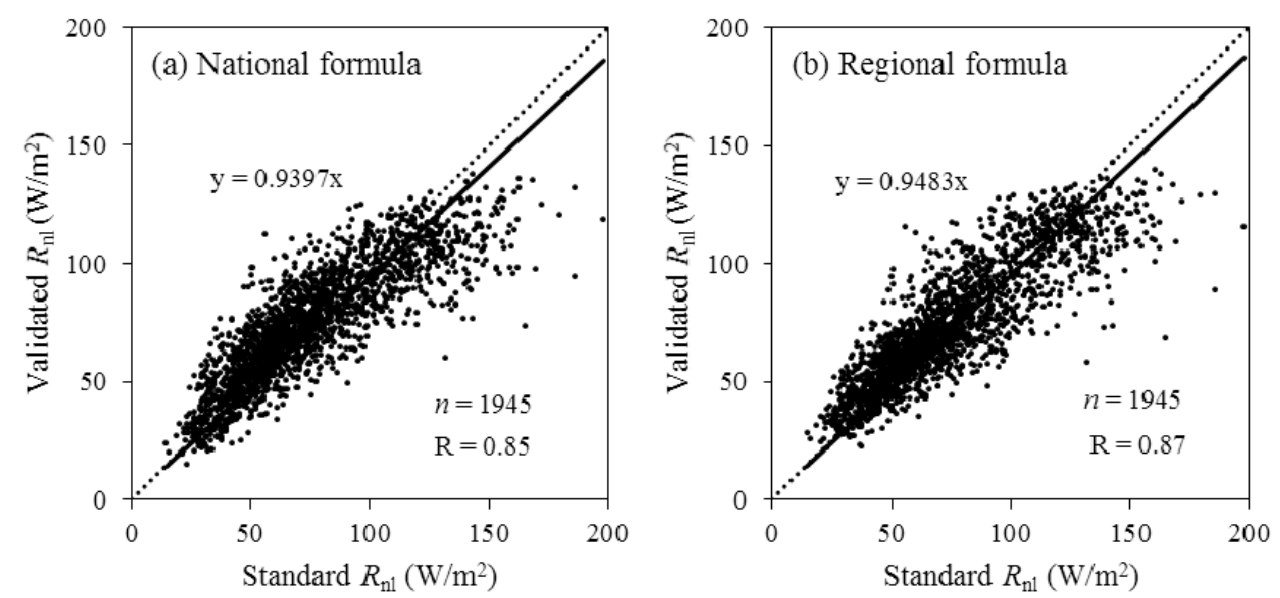

Figure 4. Correlation between the standard and validated monthly net long-wave radiation (a) national formula; (b) regional formula) at the nineteen radiation stations. 
Table 5. Revised national and regional formulas to calculate net long-wave radiation in China.

\begin{tabular}{|c|c|c|c|}
\hline Formulas & Stations Used to Modeling & Equations & Area Recommended to Use \\
\hline National formula & The whole of 19 stations listed in Table 1 & $R_{\mathrm{nl}}=\sigma\left(\frac{T_{\min }^{4}+T_{\max }^{4}}{2}\right)\left(0.47-0.13 \sqrt{e_{\mathrm{a}}}\right)\left(0.11+0.89 \frac{n_{\mathrm{s}}}{N_{\mathrm{s}}}\right)$ & Entire China \\
\hline \multirow[t]{3}{*}{ Regional formulas } & $\begin{array}{l}\text { Beijing, Chengdu, Guangzhou, Harbin, } \\
\text { Kunming, Mohe, Sanya, Shanghai, Shenyang, } \\
\text { Wenjiang, Wuhan, Zhengzhou }\end{array}$ & $R_{\mathrm{nl}}=\sigma\left(\frac{T_{\min }{ }^{4}+T_{\max }^{4}}{2}\right)\left(0.42-0.12 \sqrt{e_{\mathrm{a}}}\right)\left(0.19+0.81 \frac{n_{\mathrm{s}}}{N_{\mathrm{s}}}\right)$ & Eastern area of China \\
\hline & $\begin{array}{l}\text { Ejin Banner, Kashgar, Lanzhou, Urumuqi, } \\
\text { Yuzhong }\end{array}$ & $R_{\mathrm{nl}}=\sigma\left(\frac{T_{\min }{ }^{4}+T_{\max }^{4}}{2}\right)\left(0.42-0.06 \sqrt{e_{\mathrm{a}}}\right)\left(0.09+0.91 \frac{n_{\mathrm{s}}}{N_{\mathrm{s}}}\right)$ & Northwestern area of China \\
\hline & Golmud, Lhasa & $R_{\mathrm{nl}}=\sigma\left(\frac{T_{\min }{ }^{4}+T_{\max }^{4}}{2}\right)\left(0.46-0.12 \sqrt{e_{\mathrm{a}}}\right)\left(0.32+0.68 \frac{n_{\mathrm{s}}}{N_{\mathrm{s}}}\right)$ & Tibetan Plateau \\
\hline
\end{tabular}

Table 6. Comparison of the standard and validated net long-wave radiation of the nineteen radiation stations based on the revised national and regional formulas.

\begin{tabular}{|c|c|c|c|c|c|c|c|c|}
\hline \multirow{2}{*}{$\begin{array}{ll} & \text { Errors } \\
\text { Station } & \end{array}$} & \multicolumn{2}{|c|}{$\operatorname{MBE}\left(W / m^{2}\right)$} & \multicolumn{2}{|c|}{$\operatorname{MABE}\left(\mathrm{W} / \mathrm{m}^{2}\right)$} & \multicolumn{2}{|c|}{ MAPE (\%) } & \multicolumn{2}{|c|}{ RMSE $\left(W / m^{2}\right)$} \\
\hline & $\begin{array}{l}\text { National } \\
\text { Formula }\end{array}$ & $\begin{array}{c}\text { Regional } \\
\text { Formula }\end{array}$ & $\begin{array}{l}\text { National } \\
\text { Formula }\end{array}$ & $\begin{array}{c}\text { Regional } \\
\text { Formula }\end{array}$ & $\begin{array}{l}\text { National } \\
\text { Formula }\end{array}$ & $\begin{array}{c}\text { Regional } \\
\text { Formula }\end{array}$ & $\begin{array}{l}\text { National } \\
\text { Formula }\end{array}$ & $\begin{array}{l}\text { Regional } \\
\text { Formula }\end{array}$ \\
\hline Beijing & 6.062 & 1.667 & 10.999 & 9.451 & 16.468 & 13.755 & 13.351 & 11.810 \\
\hline Chengdu & -1.433 & 1.334 & 6.062 & 5.836 & 16.010 & 16.199 & 7.966 & 7.624 \\
\hline Ejin Banner & -12.760 & -13.870 & 18.317 & 17.545 & 13.930 & 13.189 & 24.460 & 24.263 \\
\hline Golmud & -3.966 & 5.671 & 12.389 & 11.556 & 11.915 & 12.353 & 14.804 & 14.069 \\
\hline Guangzhou & 5.987 & 5.674 & 8.893 & 7.633 & 20.530 & 18.814 & 11.586 & 9.817 \\
\hline Harbin & -3.596 & -6.722 & 12.149 & 12.168 & 16.021 & 15.571 & 16.292 & 17.012 \\
\hline Kashgar & 5.154 & 8.064 & 17.366 & 17.258 & 22.973 & 22.674 & 21.290 & 20.924 \\
\hline Kunming & 1.398 & -2.003 & 9.133 & 8.477 & 13.311 & 12.088 & 11.855 & 11.515 \\
\hline Lanzhou & 0.351 & 2.086 & 9.911 & 9.901 & 12.237 & 12.639 & 12.457 & 12.432 \\
\hline Lhasa & -18.152 & -7.855 & 22.229 & 17.911 & 18.108 & 16.064 & 28.025 & 22.961 \\
\hline Mohe & 3.857 & 0.545 & 13.355 & 12.485 & 23.368 & 21.043 & 15.959 & 15.323 \\
\hline Sanya & 1.840 & -1.887 & 11.359 & 10.700 & 20.029 & 17.944 & 14.247 & 13.530 \\
\hline Shanghai & 2.543 & 1.367 & 7.671 & 7.269 & 15.863 & 14.885 & 9.821 & 9.129 \\
\hline Shenyang & -0.560 & -4.246 & 14.871 & 14.330 & 21.271 & 19.592 & 19.251 & 19.291 \\
\hline Urumuqi & -3.449 & -1.969 & 14.216 & 12.875 & 17.866 & 16.649 & 19.326 & 17.657 \\
\hline Wenjiang & -3.927 & -0.925 & 7.595 & 6.844 & 19.754 & 19.035 & 9.127 & 8.562 \\
\hline Wuhan & 8.449 & 7.134 & 12.434 & 11.451 & 27.807 & 26.069 & 15.069 & 14.104 \\
\hline Yuzhong & -8.907 & -7.817 & 16.649 & 16.280 & 17.119 & 17.388 & 22.734 & 20.804 \\
\hline Zhengzhou & -0.046 & -1.610 & 9.437 & 9.092 & 15.097 & 14.193 & 11.984 & 11.786 \\
\hline Average & -1.113 & -0.808 & 12.370 & 11.530 & 17.878 & 16.850 & 15.769 & 14.874 \\
\hline
\end{tabular}


As a whole, the average MABE, MAPE, RMSE, and absolute MBE of the 19 stations using the regional formula were smaller than those using the national formula (Table 6). Furthermore, the $R_{\mathrm{nl}}$ based on the regional formula showed less MABE, MAPE, and RMSE than that based on the national formula for most stations. The accuracy of the estimated $R_{\mathrm{nl}}$, in particular, was significantly improved by the regional formula at the stations located in Eastern China (e.g., Beijing, Chengdu, Guangzhou, Harbin, Kunming, Mohe, Sanya, Shanghai, Shenyang, Wenjiang, Wuhan, and Zhengzhou) and the Tibetan Plateau, while it was slightly improved at the stations located in the northwestern area (e.g., Ejin Banner, Kashgar, Lanzhou, Urumuqi, and Yuzhong) compared with the national formula. The results show that the regional formula was more accurate at estimating $R_{\mathrm{nl}}$ in China than the national formula, and it is essential to separate the eastern and northwestern areas, as well as the Tibetan Plateau, in the development of the method for the determination of $R_{\mathrm{nl}}$.

Figure 5 shows the cumulative frequency of MAPE between the standard and estimated monthly net long-wave radiation values based on the seven existing empirical formulas, two refitted formulas, and CERES data. The frequency of MAPE less than $10.0 \%$ was $40 \%$ and $35 \%$ for the revised regional and national formulas, respectively, followed by Tong Hongliang, Deng Genyun, and Penman formulas, as well as CERES data with the frequency са. 30\%, while the frequency did not exceed $5 \%$ for Верлянд, FAO24, and FAO56-PM formulas. The frequency of MAPE less than 15.0\% and $20.0 \%$ had similar characteristics. When MAPE was over 40.0\%, the frequency exceeded 50\% for Верлянд, FAO24 and FAO56-PM formulas. However, the frequency was less than $10 \%$ for the revised regional and national formulas. These results illustrated that the calibrated formulas improved the accuracy of estimating $R_{\mathrm{nl}}$ over China compared with the original ones, and were more accurate than the estimations based on the CERES data.

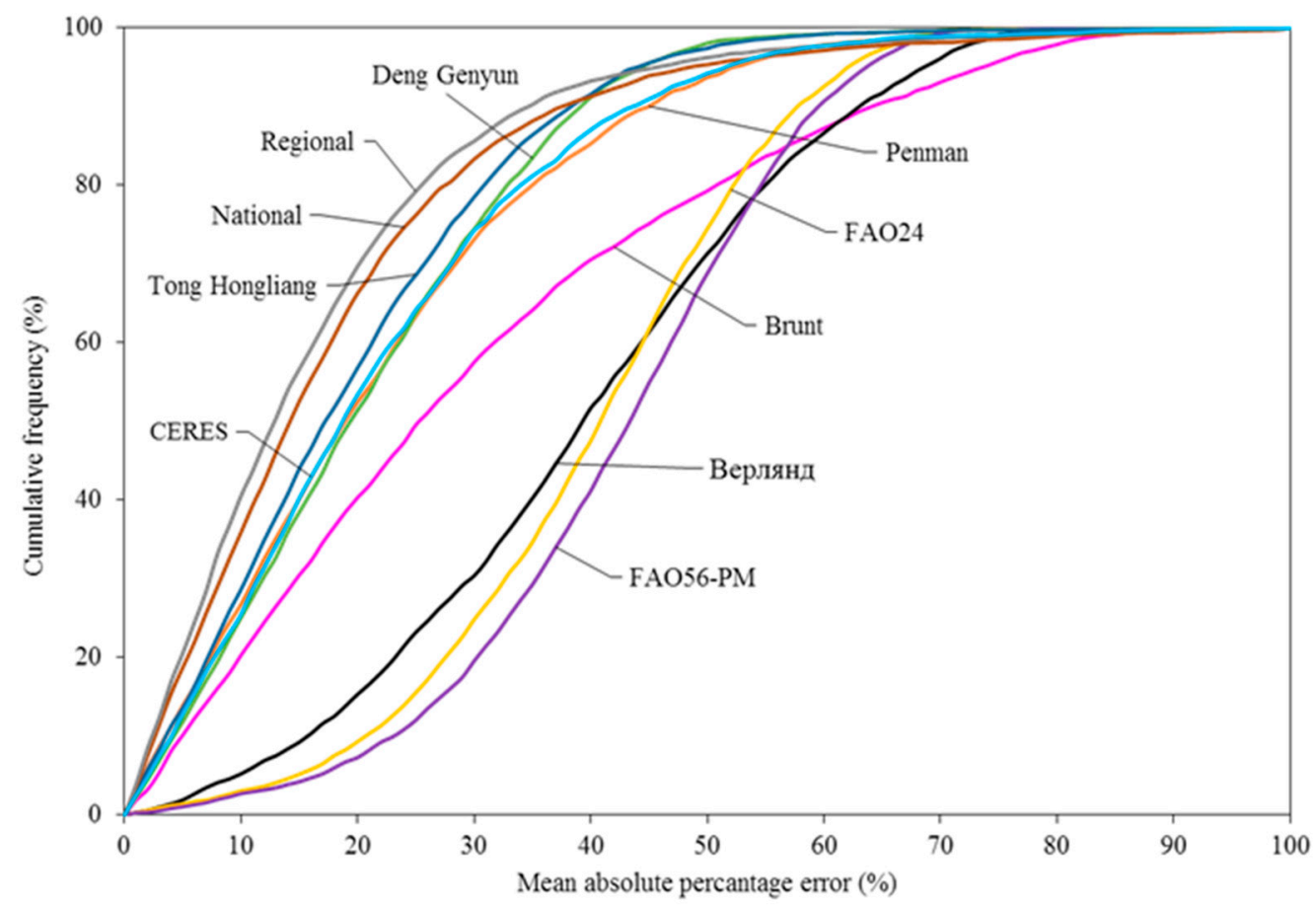

Figure 5. Cumulative frequency of MAPE between the standard and estimated monthly net long-wave radiation based on the nine empirical formulas and the CERES data.

Compared with the other five existing formulas, the Deng Genyun and Tong Hongliang formulas were more accurate at estimating $R_{\mathrm{nl}}$. Therefore, based on the radiation and observed meteorological data of the 19 radiation stations over China for the full 20 years, we compared the MBE, MABE, MAPE, and RMSE of the standard and estimated $R_{\mathrm{nl}}$ using the revised regional, the Deng Genyun, and the 
Tong Hongliang formulas to illustrate the effect of the parameter optimization more clearly. Taking the 19 stations as a whole, the correlation between the estimated and standard $R_{\mathrm{nl}}$ using the regional formula was higher than that for the Deng Genyun and Tong Hongliang formulas (Table 7). The MBE of the regional formula was $-0.59 \mathrm{~W} / \mathrm{m}^{2}$ and the absolute value was much smaller than that of the other two formulas. The regional formula also produced a lower MABE, MAPE, and RMSE, indicating that it was more accurate than the Deng Genyun and Tong Hongliang formulas.

Table 7. Comparison of the standard and estimated monthly net long-wave radiation based on the regional, Deng Genyun, and Tong Hongliang formulas.

\begin{tabular}{cccccc}
\hline Formulas & $\mathbf{R}$ & MBE $\left(\mathbf{W} / \mathbf{m}^{\mathbf{2}}\right)$ & MABE $\left(\mathbf{W} / \mathbf{m}^{\mathbf{2}}\right)$ & MAPE $(\%)$ & RMSE $\left(\mathbf{W} / \mathbf{m}^{\mathbf{2}}\right)$ \\
\hline Regional & 0.870 & -0.590 & 11.536 & 16.601 & 15.432 \\
Deng Genyun & 0.860 & -14.441 & 17.871 & 20.965 & 24.606 \\
Tong Hongliang & 0.827 & -10.027 & 15.107 & 19.562 & 20.092 \\
\hline
\end{tabular}

For most of the 19 stations, the RMSE of the $R_{\mathrm{nl}}$ based on the regional formula was the smallest among the three formulas (Figure 6). In particular, the regional formula was clearly more accurate than the Deng Genyun formula at the stations located in Northwestern China (e.g., Ejin Banner, Kashgar, Lanzhou, Urumuqi, and Yuzhong) and the Tibetan Plateau. It was also clearly more accurate than the Tong Hongliang formula at the stations located in the eastern area (e.g., Beijing, Chengdu, Guangzhou, Harbin, Kunming, Mohe, Sanya, Shanghai, Shenyang, Wenjiang, Wuhan, and Zhengzhou). Therefore, we recommend this formula as the standard climatology method to calculate the net long-wave radiation over China.

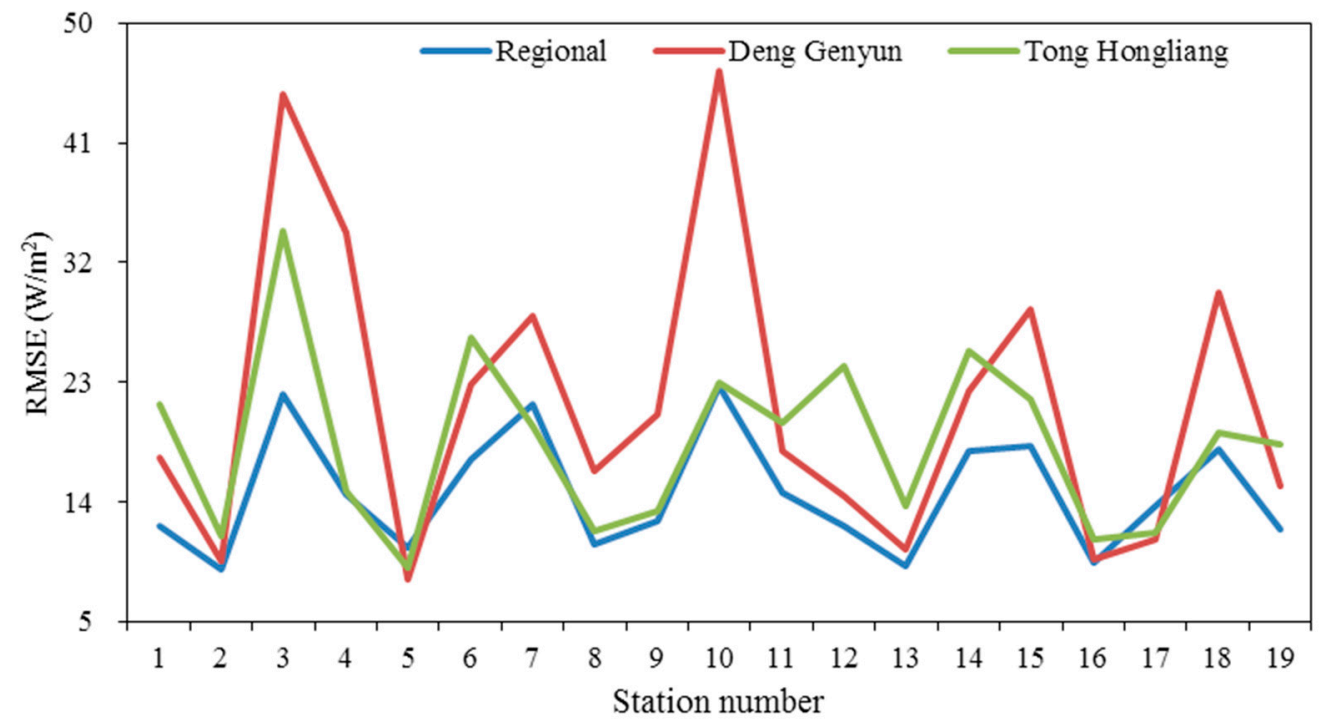

Figure 6. RMSE of the regional, Deng Genyun, and Tong Hongliang formulas compared with the standard net long-wave radiation at nineteen stations in China.

\section{Conclusions}

The performance of empirical formulas for the estimation of monthly net long-wave radiation $\left(R_{\mathrm{nl}}\right)$, with both original parameter values and recalibrated parameters, was tested and compared at 19 radiation stations in China. Meanwhile, the accuracy of the CERES EBAF-Surface Ed 2.8 estimated $R_{\mathrm{nl}}$ also evaluated, along with others from the seven formulas. The monthly $R_{\mathrm{nl}}$ over China was underestimated by all of the existing formulas with original parameters. The Tong Hongliang formula was the best among these methods for estimating $R_{\mathrm{nl}}$ over China, as a whole, followed by the Penman and the Deng Genyun formulas. The estimated $R_{\mathrm{nl}}$ based on the CERES data also showed relatively 
higher precision in accordance with the three formulas mentioned above. The FAO56-PM formula, with the lowest precision, was not applicable to China. For individual stations, the accuracy of the Deng Genyun formula was the highest on the eastern plain, while the Tong Hongliang formula was suitable for the plateau area because it includes altitude correction in the atmospheric moisture calculation. The revised formulas with recalibrated parameters were more accurate than the seven original formulas and the estimation based on the CERES data. Furthermore, the regional formula produced smaller errors than the formula for the whole of China at most stations, indicating that it is necessary to distinguish different areas in the development of new methods to determine $R_{\mathrm{nl}}$. The regional formulas were clearly more accurate than the Deng Genyun formula at the stations located in Northwestern China and the Tibetan Plateau, and were clearly more accurate than the Tong Hongliang formula at the stations located in the eastern area. Therefore, the regional formulas developed in this study are recommended as the standard climatology methods to calculate the monthly net long-wave radiation over China.

Compared with other meteorological factors, the low number of stations, short data length, and relatively large observation errors of surface radiation balance components were the main factors limiting the generality of the results drawn from this study over China. Therefore, multi-source data, such as remote sensing and sounding data, must be applied to develop future net long-wave radiation methods. According to this paper, there are discrepancies between observations and estimations from CERES data at the stations over China, which may be mainly caused by cloud. The difference between the meteorological assimilation data from reanalysis and the actual data may be another cause leading to the error in surface $R_{\mathrm{nl}}$ fluxes. However, with the development of technology, the accuracy of satellite-based data will be improved further. Another future study will be carried out to establish separate formulas for the four seasons to improve the precision and accuracy of the net long-wave radiation calculation. In addition, it should be calculated that $R_{\mathrm{nl}}$ under clear-sky and all-sky conditions in China in the future, following the previous study [48].

Acknowledgments: This investigation was financially supported by the Jiangsu Key Laboratory of Agricultural Meteorology Foundation (grant number KYQ1205) and by the National Natural Science Foundation of China (grant number 41405111).

Author Contributions: Wen Cao and Shuanghe Shen proposed the idea. Chunfeng Duan and Yun Yao processed and analyzed the data. Wen Cao and Chunfeng Duan wrote the paper.

Conflicts of Interest: The authors declare no conflict of interest.

\section{References}

1. Rodskjer, N. Net long-wave radiation at Uppsala, Sweden. Theor. Appl. Climatol. 1979, 27, 189-192. [CrossRef]

2. Zhou, S.Z.; Zhang, R.R.; Zhang, C. Meteorology and Climatology; Higher Education Press: Beijing, China, 1990; pp. 40-42.

3. Jimenez, J.I.; Alados-Arboledas, L.; Castro-Diez, Y.; Ballester, G. On the estimation of long-wave radiation flux from clear skies. Theor. Appl. Climatol. 1987, 38, 37-42. [CrossRef]

4. Trnka, M.; Zalud, Z.; Eitzinger, J.; Dubrovský, M. Global solar radiation in Central European lowlands estimated by various empirical formulae. Agric. For. Meteorol. 2005, 131, 54-76. [CrossRef]

5. Angstrom, A.K. On the variation of the atmosphere radiation. Gerl. Beitr. Geophys. 1925, 4, $21-145$.

6. Brunt, D. Notes on radiation in the atmosphere. I. Quart. J. R. Meteor. Soc. 1932, 58, 389-420. [CrossRef]

7. Lu, B. Probe into the calculating method of evaporation capacity in Poyang Lake. Jiangxi Hydraul. Sci. Technol. 1994, 20, 347-354.

8. Penman, H.L. Natural Evaporation from Open Water, Bare Soil and Grass. Proc. R. Soc. 1948, A193, $120-145$. [CrossRef]

9. Swinbank, W.C. Long-wave radiation from clear skies. Quart. J. R. Meteorol. Soc. 1963, 89, 339-348. [CrossRef]

10. Idso, S.B.; Jackson, R.D. Thermal radiation from the atmosphere. J. Geophys. Res. 1969, 74, 5397-5403. [CrossRef] 
11. Doorenbos, J.; Pruitt, W.O. Guidelines for Predicting Crop. Water Requirements; Food and Agriculture Organization of the United Nations: Rome, Italy, 1977; p. 27.

12. Allen, R.G.; Perreira, L.S.; Raes, D. Crop. Evapotranspiration: Guidelines for Computing Crop. Water Requirements; Food and Agriculture Organization of the United Nations: Rome, Italy, 1998; pp. 51-52.

13. Matsui, H. Comparison of net longwave radiation equation in penman-type evapotranspiration equation. Trans. Jap. Soc. Irrig. Drain. Rural Eng. 2011, 78, 531-536.

14. Matsui, H.; Osawa, K. Calibration effects of the net longwave radiation equation in Penman-Type methods at Tateno, Japan. Hydrol. Res. Lett. 2015, 9, 113-117. [CrossRef]

15. Tong, H.L. A climatic calculation method for the evaporation power in China. J. Nanjing Inst. Meteorol. 1989, 12, 19-33.

16. Deng, G.Y. A climatic calculative method of evaporation from open water. Acta Meteorol. Sin. 1979, 37, 87-96.

17. Ji, G.L.; Jiang, H.; Zha, S.F. The computation and some distribution characteristics of effective radiation over the Qinghai-Xizang Plateau and its adjacent areas. Plateau Meteorol. 1987, 6, 141-149.

18. Li, R.; Zhao, L.; Wu, T.H.; Wu, X.D.; Xiao, Y.; Du, Y.Z.; Qin, Y.H. The impacts of net long-wave radiation on the surface soil thermal regimes over the Qinghai-Tibetan Plateau, China. Environ. Earth Sci. 2016. [CrossRef]

19. Reed, R.K. Variations in oceanic net long-wave radiation caused by atmospheric thermal structure. J. Geophys. Res. Atmos. 1975, 80, 3819-3820. [CrossRef]

20. Reed, R.K. On estimation of net long-wave radiation from the oceans. J. Geophys. Res. Atmos. 1976, 81, 5793-5794. [CrossRef]

21. Siegel, D.A.; Dickey, T.D. Variability of net longwave radiation over the eastern North Pacific Ocean. J. Geophys. Res. Atmos. 1986, 91, 7657-7666. [CrossRef]

22. Allan, R.P.; Slingo, A. Simulated long-wave clear-sky irradiance over the ocean: Spatial and temporal variability 1979-1993. Phys. Chem. Earth 1998, 23, 599-604. [CrossRef]

23. Zapadka, T.; Woźniak, S.B.; Woźniak, B. A simple formula for the net long-wave radiation flux in the southern Baltic Sea. Oceanologia 2001, 43, 265-277.

24. Zapadka, T.; Woźniak, B.; Dera, J. A more accurate formula for calculating the net longwave radiation flux in the Baltic Sea. Oceanologia 2007, 49, 449-470.

25. Yao, Y.J.; Zhao, S.H.; Zhang, Y.H.; Jia, K.; Liu, M. Spatial and Decadal Variations in Potential Evapotranspiration of China Based on Reanalysis Datasets during 1982-2010. Atmosphere 2014, 5, 737-754. [CrossRef]

26. Gao, G.; Chen, D.L.; Ren, G.Y.; Chen, Y.; Liao, Y.M. Spatial and temporal variations and controlling factors of potential evapotranspiration in China: 1956-2000. J. Geogr. Sci. 2006, 16, 3-12. [CrossRef]

27. Xu, C.Y.; Gong, L.; Tong, J.; Chen, D. Decreasing reference evapotranspiration in a warming climate-A case of Changjiang (Yangtze) river catchment during 1970-2000. Adv. Atmos. Sci. 2006, 23, 513-520. [CrossRef]

28. Li, Z.L.; Li, Z.J.; Xu, Z.X.; Zhou, X. Temporal variations of reference evapotranspiration in Heihe River basin of China. Hydrol. Res. 2013, 44, 904-916. [CrossRef]

29. Shi, Z.J.; Xu, L.H.; Yang, X.H.; Shan, N. Trends in reference evapotranspiration and its attribution over the past 50 years in the Loess Plateau, China: Implications for ecological projects and agricultural production. Stoch. Environ. Res. Risk A 2016, 31, 1-17. [CrossRef]

30. Zhang, X.Q.; Ren, Y.; Yin, J.; Zheng, D. Spatial and temporal variation patterns of reference evapotranspiration across the Qinghai-Tibetan Plateau during 1971-2004. J. Geophys. Res. 2009. [CrossRef]

31. Zhang, Y.Q.; Liu, C.M.; Tang, Y.H.; Yang, Y.H. Trends in pan evaporation and reference and actual evapotranspiration across the Tibetan Plateau. J. Geophys. Res. 2007. [CrossRef]

32. Gao, Z.D.; He, J.S.; Dong, K.B.; Bian, X.D.; Li, X. Sensitivity study of reference crop evapotranspiration during growing season in the West Liao River basin, China. Theor. Appl. Climatol. 2016, 124, 1-17. [CrossRef]

33. Huo, Z.L.; Shi, H.B.; Chen, Y.X.; Qu, Z.Y. Spatiotemporal variation and dependence analysis of $\mathrm{ET}_{0}$ in north arid and cold region. Trans. Chin. Soc. Agric. Eng. 2004, 20, 60-63.

34. CERES EBAF-Surface Product. Available online: https://ceres.larc.nasa.gov/products.php?product=EBAFSurface (accessed on 6 May 2017).

35. Sun, Z.A.; Weng, D.M. Climatological calculation and distributional features of effective radiation over China part II: Empirical computation method and distributional features. J. Nanjing Inst. Meteorol. 1986, 4, 335-347. 
36. Zhu, X.C.; Qiu, X.F.; Zeng, Y.; He, Y.J.; Liu, H.B. The research on the estimation method of effective radiation in China based on remote sensing data. J. Yunnan Univ. 2014, 36, 674-682.

37. Cao, W.; Duan, C.F.; Yang, T.M.; Liu, R.N. The evaluation and parameter optimization of surface effective radiation climatology model. Acta Meteorol. Sin. 2016, 74, 947-958.

38. Weng, D.M.; Feng, Y.H. Analysis on the characteristics of effective radiation and atmospheric radiation in summer on the Tibetan Plateau. Chin. Sci. Bull. 1984, 13, 796-799.

39. Bian, L.G.; Lu, L.H.; Lu, C.G.; Chen, Y.J.; Gao, Z.Q. The characteristics of radiation balance components of the Tibetan Plateau in the summer of 1998. Chin. J. Atmos. Sci. 2001, 25, 577-588.

40. Sun, Z.A.; Weng, D.M. Climatological calculation and distributional features of effective radiation over China part I: Theoretical discussion of calculation methodology. J. Nanjing Inst. Meteorol. 1986, 3, 228-238.

41. Li, R.; Zhao, L.; Ding, Y.J.; Shen, Y.P.; Ji, G.L.; Liu, G.Y.; Du, E.J.; Xiao, Y.; Sun, L.C.; Liu, Y.; et al. Variations of Surface Effective Radiation and Its Effect on Superficial Ground Temperatures on Tibetan Plateau. J. Glaciol. Geocryol. 2011, 33, 1022-1032.

42. Lhomme, J.P.; Vacher, J.J.; Rocheteau, A. Estimating downward long-wave radiation on the Andean Altiplano. Agric. For. Meteorol. 2007, 145, 139-148. [CrossRef]

43. Stone, R.J. Improved statistical procedure for the evaluation of solar radiation estimation models. Sol. Energy 1993, 5, 289-291. [CrossRef]

44. Jacovides, C.P.; Kontoyiannis, H. Statistical procedures for the evaluation of evapotranspiration computing models. Agric. Water Manag. 1995, 27, 365-371. [CrossRef]

45. Itenfisu, D.; Elliott, R.L.; Allen, R.G.; Walter, I.A. Comparison of reference evapotranspiration calculation as part of the ASCE standardization effort. J. Irrig. Drain. Eng. 2003, 129, 440-448. [CrossRef]

46. Duan, C.F.; Cao, W.; Huang, Y.; Wen, H.Y.; Liu, J.J. Effect of time resolution of meteorological variables on estimation of reference evapotranspiration. Trans. Chin. Soc. Agric. Eng. 2015, 31, 158-164.

47. Yin, Y.H.; Wu, S.H.; Zheng, D.; Yang, Q.Y. Radiation calibration of FAO56 Penman-Monteith model to estimate reference crop evapotranspiration in China. Agric. Water Manag. 2008, 95, 77-84. [CrossRef]

48. Bilbao, J.; De Miguel, A. Estimation of daylight downward longwave atmospheric irradiance under clear-sky and all-sky conditions. J. Appl. Meteorol. Clim. 2007, 46, 878-889. [CrossRef]

(C) 2017 by the authors. Licensee MDPI, Basel, Switzerland. This article is an open access article distributed under the terms and conditions of the Creative Commons Attribution (CC BY) license (http://creativecommons.org/licenses/by/4.0/). 